Disponível em

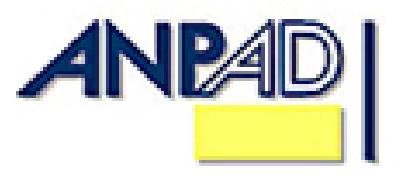

\title{
Análise de Decisões sobre Uso de Tecnologia: um Estudo no Setor de Telefonia Móvel Fundamentado nos Axiomas da Economia Comportamental
}

\author{
Analysis of Decisions on the Use of Technology: a Study in the Mobile Telephone Sector \\ Grounded in the Axioms of Behavioral Economics
}

\author{
Alexandre Cappellozza * \\ E-mail: cappellozza@gmail.com \\ Fundação Getúlio Vargas - EAESP/FGV \\ São Paulo, SP, Brasil. \\ Otavio Prospero Sanchez \\ E-mail: otavio.sanchez@fgv.br \\ Fundação Getúlio Vargas - EAESP/FGV \\ São Paulo, SP, Brasil.
}

Copyright (C) 2011 RAC. Todos os direitos, até mesmo de tradução, são reservados. É permitido citar parte de artigos sem autorização prévia, desde que seja identificada a fonte. 


\title{
Resumo
}

A Economia Comportamental, campo que recebeu grandes contribuições de Kahneman e Tversky e que rendeu um prêmio Nobel ao primeiro, é uma abordagem que se tem ocupado em caracterizar e analisar variados aspectos do comportamento decisório humano, descrevendo-o como não plenamente racional. Sua importância está em questionar a racionalidade da Teoria da Utilidade Esperada, TUE, aceito por décadas como modelo fundamental na economia. O objetivo deste artigo é verificar como as decisões sobre a adoção e uso de equipamentos e serviços apoiados por tecnologia são afetadas pelos aspectos influenciadores da decisão, preconizados por Kahneman e Tversky. Para tanto, o trabalho foi conduzido por meio de experimento adaptado ao contexto do segmento de telefonia móvel, setor esse escolhido pela sua relevância nos últimos anos na economia brasileira. Os dados foram analisados por técnicas de comparação de grupos com variáveis categóricas. Os resultados permitiram evidenciar vários aspectos da não-racionalidade dos decisores conforme apregoado pelos autores originais, especialmente em relação a aspectos contidos na chamada Teoria dos Prospectos (Prospect Theory). A partir das descobertas, pode-se questionar decisões sobre a utilização de tecnologia no nível do indivíduo e organizações, com importantes conseqüências no nível gerencial.

Palavras-chave: teoria dos prospectos; economia comportamental; decisões de TI; usos de TI.

\begin{abstract}
Behavioral economics, a field that has received major contributions from Kahneman and Tversky, the former also having received a Nobel prize, is an approach that has focused on a number of aspects of behavior in human decisions, defining their outcomes as not being fully rational. Its main contribution was conquered by questioning the so far very well established Utility Theory, a very important basis in economics. This article aims to verify how decisions concerning the adoption and use of information technology are potentially affected by the factors described in Kahneman and Tversky's theory. This was done by means of an experiment adapted to the context of the mobile communications sector, which was chosen due to its economic and social relevance in recent years in Brazil. The data were analyzed by means of categorical group comparison techniques. The results provided evidence of non-rational behavior amongst decision makers as proposed by original authors, mainly those regarding aspects of the Prospect Theory. With this evidence, it is possible to question a number of aspects of individual and organizational decisions involving the use of information technology use, with important implications at the managerial levels.
\end{abstract}

Key words: prospect theory; behavioral economics; IT decisions; use of IT. 


\section{Introdução}

Uma das fundamentais características das teorias tradicionais de decisão, especialmente a Teoria da Utilidade Esperada, TUE, é a de procurar explicar a maneira como os agentes escolhem (ou deveriam escolher) uma específica ação a ser executada em dado instante, entre várias ações disponíveis. A TUE pressupõe que o decisor seja racional e capaz de ordenar preferências de maneira consideravelmente precisa. Assim, o decisor seria capaz de associar a cada ação um valor real, representando como a utilidade prevista de cada alternativa, e executar a ação, cuja utilidade prevista é a mais elevada entre todas. Esta teoria, entre outros conceitos, define que há condições da maximização racional da utilidade esperada, em contexto provável dos fatos relevantes que são oferecidos aos decisores (Neuman \& Morgenstern, 1947).

Como premissa para esta maximização, a Teoria da Utilidade Esperada requer que o decisor conheça todas as alternativas possíveis e suas consequências; mas esta completude de informação sobre as eventuais consequências e respectivas alternativas de cada escolha nem sempre está disponível, de acordo com a proposição de Simon (1987), em sua Teoria da Racionalidade Limitada.

Considerando a incompletude informacional e outros aspectos relacionados às decisões, a teoria da racionalidade limitada considera a limitação da habilidade humana com as variáveis ambientais que existem no mundo real, a adaptação do indivíduo a ambientes complexos e sua tendência de procurar a solução para um problema decisório que, devido às limitações de tempo e de trabalho mental, são imperfeitas (Kalil, Melo, \& Schneider, 2006; Simon, 1991).

A partir da eventual indisponibilidade de informações sobre todas alternativas e suas consequências em uma decisão, pode-se admitir uma situação de não-racionalidade Simoniana clássica. Assim, enquanto o termo decisão racional se refere a uma decisão analítica, o termo nãoracional pode ser utilizado para decisões parcialmente intuitivas pela incapacidade de obter informações essenciais para a decisão. Em decisões não-racionais, sob julgamentos, a tomada de decisão pode não obedecer a uma análise sequencial da situação, nem prever fielmente as consequências da decisão. Além disto, como resultado de experiências prévias, os tomadores de decisão podem imprimir rapidez na tomada de decisão com maior confiança quanto à validade de suas decisões intuitivas, embora nem sempre corretas (Simon, 1987; Simon et al., 1987).

Como consequência, a contraposição entre a aceitação da teoria racional e as dificuldades que ocorrem na realidade pode levar à conclusão de que uma decisão racional e ótima está frequentemente além da capacidade da maioria dos indivíduos; ocorre que os julgamentos são afetados pelos hábitos, tradições, crenças, relacionamentos sociais, interesses, objetivos, experiências, entre outros fatores de influência. Estes fatores de influência resultam em um conjunto abstrato e interativo, que pode configurar um cenário complexo demais para a decisão que pretende ser tomada, visando ao melhor dos interesses do indivíduo (Mackenzie, 2004).

Quando a situação envolve eventos incertos, as probabilidades subjetivas geradas por julgamentos pessoais tendem a ser estimadas por heurísticas dos indivíduos e grupos e, ocasionalmente, estas heurísticas podem estar associadas. Isso pode levar a erros graves e sistemáticos nas decisões tomadas (Kahneman \& Tversky, 1974; Loomes \& Sugden, 1982). Além disto, outros fatores também podem alterar este processo; por exemplo, lealdade, confiança, experiência, marcas, reputação, intuição, satisfação, entre outros (Brei \& Rossi, 2005; Chen \& Hitt, 2002; Espinoza \& Larán, 2006).

Como consequências das limitações da TUE, a Teoria dos Prospectos - TP, ou Teoria das Perspectivas, ou ainda Teoria das Expectativas, como também é frequentemente conhecida, proposta por Kahneman e Tversky (1979), surge para explicar a ocorrência de certos axiomas decisórios, especialmente nas situações de risco. Segundo a Teoria das Perspectivas, o processo de tomada de decisão pode levar as pessoas a perceberem os resultados da decisão não como alterações no estado final de riqueza ou bem-estar, mas como ganhos ou perdas em relação a um ponto de 
referência, o qual a pessoa assume para a situação de decisão (Kahneman \& Tversky, 1979). Assim, os pesquisadores contestam o conceito de que o ser humano seria capaz de decidir racionalmente, elaborarando sobre a complexidade dos fatores envolvidos na situação de decisão (Kalil et al., 2006).

Ao longo de seus trabalhos, Kahneman e Tversky estudaram os fatores que afetam o processo de tomada de decisão por meio de experimentos que envolvem situações cotidianas da vida econômica dos indivíduos. Assim, decisões como descontos em compras, seleção de apostas, programas de vacinação etc. foram os cenários que viabilizaram o desenvolvimento de suas pesquisas e revelaram que o comportamento decisório das pessoas nem sempre está associado a critérios que promovam a maior utilidade de suas escolhas individuais; isso frontalmente contraria a Teoria da Utilidade Esperada e desafia vários pressupostos da teoria econômica (Kahneman \& Tversky, 1979; Tversky \& Kahneman, 1981). A ocorrência de incertezas e a apresentação de riscos nas decisões, que levam à percepção de que os benefícios ou malefícios são expectativas imprecisas, foi particularmente estudada por Kahneman e Tversky; eles deram contribuições importantes com relação ao comportamento em dois diferentes domínios: o das perdas, onde se compara uma alternativa certa contra uma alternativa incerta prejudicial; e o domínio dos ganhos, onde se estuda a decisão entre uma alternativa certa e uma incerta benéfica. Nessas condições, os autores concluíram que os decisores mudam completamente suas preferências, violando regras de intransitividade que fundamentaram todo um campo de estudos econômicos neoclássicos.

No âmbito das decisões sobre investimentos e usos de tecnologia da informação e sistemas, TI, indivíduos e organizações convivem com a incerteza propiciada pela dificuldade de obtenção de completo conhecimento a respeito dos efeitos que a TI possa ter sobre as organizações e pessoas; por exemplo, na incapacidade de analisar perfeitamente diferentes tendências tecnológicas, aspectos de padronização, ações e reações da concorrência, dentre outros aspectos (Sanchez \& Albertin, 2009). Em face disso, tais características do setor de tecnologia criam um potencial cenário, para que ocorram inconsistências na tomada de decisão, em alinhamento com a perspectiva dos estudos de Kahneman e Tversky.

Este trabalho visa compreender e verificar se tais fenômenos de dissonância na decisão ocorrem em decisões do setor de tecnologia. Em particular, foi escolhido analisar o segmento de telefonia móvel, caracterizado por ser uma atividade econômica do tipo de tecnologia intensiva e de capital intensivo: permite múltiplos modelos de negócios, desenvolvimento de recursos tecnológicos variados, frequente mudança tecnológica, incompleta compreensão de benefícios por parte dos usuários, entre outras características que tornam o segmento particularmente propenso a que os fenômenos preconizados na Teoria das Perspectivas ocorram.

Além disso, o setor apresenta significativa importância na economia brasileira, comprovado pelo seu crescimento ao longo dos últimos anos. A expressiva penetração dos serviços de comunicação móvel pela população fez o setor dobrar a participação no Produto Interno Bruto (PIB) brasileiro, passando de 3,2\% em 1998 para 6,2\% em 2007: os assinantes de telefones celulares passaram de 1,7 milhões em 2002 a 133,2 milhões em 2008 (Agência Nacional de Telecomunicações [Anatel], 2008). Entretanto, apesar da expansão do número de usuários dos serviços de telefonia móvel e do crescimento econômico do setor no Brasil, aspectos como competitividade, incertezas e desafios também fazem parte do cotidiano do setor que, frequentemente, se vê às voltas com novas tecnologias (Loural \& Oliveira, 2005).

\section{Axiomas das Teorias Comportamentais de Decisão}

Além das heurísticas, que podem levar a erros sistemáticos nas decisões, Kahneman e Tversky (1979) observaram alguns comportamentos sistemáticos dos decisores, que chamaram de efeitos. 
O primeiro é o efeito certeza, que se refere à valorização pelo decisor das opções certas de ganho, em comparação com opções que envolvem alguma incerteza: independentemente de que a opção incerta proporcione maior utilidade ou valor esperado superior, fato este que contraria a TUE. O viés psicológico de valorização da certeza se traduz em maior aversão ao risco, no domínio das expectativas positivas: domínio dos ganhos.

Em contraposição, observa-se um comportamento que pode ser caracterizado de preferência ao risco no domínio das expectativas negativas: domínio das perdas (Kahneman \& Tversky, 1979). Geralmente, quando o decisor se depara com decisões que envolvem perdas certas inferiores e perdas prováveis superiores, ocorre a preferência pela alternativa que envolve as perdas prováveis superiores (Kahneman \& Tversky, 1979; Loomes \& Sugden, 1982; Pablo \& Sitkin, 1992). A esse efeito, chamouse efeito reflexão.

Assim os autores asseveram que os indivíduos tendem a evitar riscos, quando existem alternativas de ganho, ao passo que tendem a ser propensos ao risco, quando a decisão envolve alternativas com perdas, ainda que da mesma magnitude (Aldrighi \& Milanez, 2005; Kahneman \& Tversky, 1979; Pablo \& Sitkin, 1992).

O efeito framing consiste na tendência dos decisores de formularem mentalmente as alternativas da decisão, com base em aspectos externos diferentes dos seus objetivos. Esses aspectos externos formam uma referência e tem potencial para influenciar a posição atual do tomador de decisão, levando a inconsistências decisórias (Tversky \& Kahneman, 1981). Assim, alterações nas formas de apresentação ex ante das escolhas na decisão podem causar significativas diferenças nas preferências do decisor. Esta visão difere substancialmente da visão clássica da TUE, que assume os resultados da decisão como representados pelos estados ex post de riqueza (Maule \& Villejoubert, 2007; Tversky \& Kahneman, 1981).

Em seus experimentos, Kahneman e Tversky (1979) e Tversky e Kahneman (1981), associaram formas de apresentação das ofertas a indivíduos que deveriam decidir sobre elas comparativamente a outras. Para tanto, associaram a oferta de alternativas (opções) certas e prováveis, visando à inclusão de incerteza na tomada de decisão. Para permitir a formação de framing, referências de preços foram incluídas. Uma sistematização dos estudos desses autores é apresentada na Tabela 1.

Tabela 1

Fatores de Influência do Comportamento Decisório e Formas de Apresentação das Ofertas

\begin{tabular}{ccccc}
\hline $\begin{array}{c}\text { Forma de } \\
\text { apresentação de } \\
\text { ofertas }\end{array}$ & \multicolumn{2}{c}{$\begin{array}{c}\text { Fatores de influência do comportamento decisório } \\
\text { (cliente) }\end{array}$} & Referências \\
\cline { 2 - 4 } & Efeito reflexão & Efeito certeza & Efeito framing & \\
\hline $\begin{array}{c}\text { Opções prováveis e } \\
\text { certas }\end{array}$ & $\mathrm{x}$ & $\mathrm{x}$ & & $\begin{array}{c}\text { Kahneman e Tversky (1979), } \\
\text { Tversky e Kahneman (1981), } \\
\text { Favaretto (2006) }\end{array}$ \\
Referência de preços & & & & $\begin{array}{c}\text { Tversky e Kahneman (1981), } \\
\end{array}$ \\
& & & & $\begin{array}{c}\text { Smith e Nagle (1995), Hsee } \\
\text { (1998), Avila e Serpa (2004) }\end{array}$ \\
\hline
\end{tabular}

Nota. Fonte: elaboração dos autores.

De acordo com a Tabela 1, os pesquisadores elaboraram uma forma de apresentação de oferta com alternativas prováveis e alternativas certas, para verificar a manifestação dos efeitos reflexão e certeza. A segunda forma de apresentação de oferta, com referências a preços, foi elaborada para a observação do efeito framing, caso em que se refere a uma análise da decisão que envolve diferentes perspectivas de determinada oferta. 
Alguns estudos procuraram testar as proposições de Kahneman e Tversky em mercados e setores específicos; haja vista Avila e Serpa (2004), Hsee (1998) e Smith e Nagle (1995). Entretanto, não há notícias de que tenha sido avaliado o setor de tecnologia, especialmente o setor de telecomunicações, nem o segmento de telefonia móvel. Em tese, este estudo supõe que os axiomas de decisão estejam presentes no segmento e, portanto, propõem-se as seguintes hipóteses.

Hipótese 1: Decisores confrontados com uma escolha entre alternativas no segmento de telefonia móvel que apresentem incerteza de ganho preferirão a ela alternativas de ganho certo (aversão a risco).

Hipótese 2: Decisores confrontados com uma escolha entre alternativas no segmento de telefonia móvel que apresentem incerteza de perda evitarão as alternativas de perda certa (preferência pelo risco).

Hipótese 3: Ofertas feitas no setor de telefonia móvel que alteram o framing de decisão por meio de referências de preço influem e tornam a decisão não racional

\section{A Particularidade do Setor de Telefonia Móvel}

A importância do setor de telefonia no Brasil pode ser atestada em parte pelos seus números e pela expressiva transformação pela qual o setor passou nos últimos anos. A expansão do número de usuários é um exemplo disso. Em 1992, o Brasil possuía cerca de 30 mil assinantes de linhas telefônicas móveis, número que passou a mais de 140 milhões de assinantes em setembro de 2008. Já a teledensidade, que é o número de pessoas com acesso ao serviço, passou de $63 \%$ em 2007, quando em 2002 não chegava a 21\%, (ANATEL, 2008).

$\mathrm{Na}$ ponta das operadoras de serviços, essa evolução foi obtida à custa de expressivos investimentos em infraestrutura, caracterizando o segmento como de capital intensivo, tanto para a criação da infraestrutura de redes móveis, como também para a interligação destas redes com operadoras de telefonia fixa (Organization for Economic Cooperation and Development [OECD], 2003). Embora possa considerar-se a existência de um crescimento significativo do setor de telefonia móvel brasileira ao longo dos últimos anos, dificuldades e desafios fazem parte do cotidiano das operadoras; entre estas, a barreira de entrada no mercado, a portabilidade numérica e o desenvolvimento de novas tecnologias de comunicação.

Segundo artigo do jornal Valor Econômico (2009), seis dos dez maiores desafios das operadoras de telefonia se relacionam diretamente às inovações tecnológicas que estão transformando o perfil do setor. O avanço de novas tecnologias, com a criação de novos e melhores componentes eletrônicos possibilitou a convergência mundial entre as redes de computadores e telefonia, tornando economias de escopo e escala na utilização destes equipamentos pela mesma rede (OECD, 2003).

Faz parte dessa realidade, portanto, a reincidente mudança tecnológica, vista em um setor de capita intensivo, como uma grande ameaça, pois as novas tecnologias podem tanto alavancar novos negócios e promover a fidelização de clientes, como também prejudicar a sua sustentabilidade, dado seu caráter disruptivo (Christensen, Anthony, \& Roth, 2004).

Além das inovações tecnológicas de comunicação que podem modificar significativamente as receitas das operadoras, em 2009 estas organizações tiveram de cumprir a determinação da ANATEL isto é, disponibilizar a portabilidade numérica telefônica ao assinante. De acordo com uma pesquisa realizada por Viard (2007), apesar da existência de custos de troca ao fornecedor, referente à reconfiguração dos sistemas telefônicos e revisão dos acordos contratuais estabelecidos entre o fornecedor e o cliente, para disponibilizar a portabilidade numérica telefônica, os custos de troca dos clientes foram reduzidos significativamente com a portabilidade telefônica, o que tornou o mercado de telefonia ainda mais competitivo. 
Além da barreira de entrada relacionada à incerteza inerente a se competir neste mercado, também deve ser considerado que as operadoras de telefonia competem em diferentes segmentos de clientes com diversos tipos de ofertas, direcionadas a clientes com contratos pós-pagos e clientes com contratos pré-pagos. Este fato pode transformar a competição entre as operadoras de telefonia atuantes diferenciadas por segmentos, ofertas e estruturas de preços (Masuda \& Whang, 2006).

Sendo o setor de capital intensivo, tal turbulência pode ser vista como risco adicional ao negócio. Em situações assim, empresas participantes em setores de capital intensivo tendem a adotar uma estratégia de garantir a escala, tornando a competição por clientes particularmente acirrada. Em setores de capital intensivo, a competição por clientes é tão intensa que tende a se processar até o exercício do nível do custo marginal (Milgrom \& Roberts, 1992). Em vista disso, entende-se que as operadoras utilizarão todos os mecanismos possíveis para manter clientes existentes e capturar novos clientes.

Adicionalmente, o setor de telefonia móvel tem-se caracterizado pela oferta intensiva de subsídios, na forma de concessão de aparelhos condicionados à assinatura de planos mais longos (Cruz, 2004). É, portanto, de supor que tal prática disseminada no mercado possa ter efeito de influenciar decisores consumidores. A partir daí, formula-se a seguinte proposição para o setor.

Hipótese 4a: Ofertas de subsídio feitas no setor de telefonia móvel alteram o framing de decisão no domínio dos ganhos e, portanto, são influentes e tornam a decisão não racional.

Hipótese 4b: Ofertas de subsídio feitas no setor de telefonia móvel alteram o framing de decisão no domínio das perdas e, portanto, são influentes e tornam a decisão não racional.

\section{Metodologia}

Para alcançar seus objetivos, esta pesquisa executou um experimento derivado dos estudos originais de Kahneman e Tversky. O estudo original buscou a comparação dos efeitos de tratamentos sobre grupos expostos a variadas situações que incluíram diferentes variáveis de controle.

Da mesma forma que os estudos originais de Kahneman e Tversky, a exposição dos grupos às situações se fez por meio de questionários, sem o uso de incentivos explícitos, como o uso de valores monetários. Esse é um aspecto discutido sobre a prática de experimentos, quando aplicados ao teste de teorias em economia comportamental. Adotamos a abordagem consistente com Camerer (1989), que investigou o efeito dos incentivos aplicados a experimentos em diversos temas; ele concluiu que os participantes, independentemente da existência e valor dos incentivos à participação dos experimentos, respondem, essencialmente, da mesma maneira e tomam as mesmas decisões.

Entre outros conceitos, Tversky e Kahneman (1992) complementam a pesquisa de Camerer (1989): confirmam a semelhança dos comportamentos decisórios mediante a oferta de incentivos aos participantes do experimento. Segundo estes autores, não se encontraram diferenças significativas nos resultados dos experimentos que pudessem alterar qualquer conclusão qualitativa significante a respeito destas teorias decisórias.

Na mesma linha, Kachelmeier e Shehata (1992) investigaram a influência da oferta de incentivos substanciais durante os experimentos, quando foram ofertadas quantias equivalentes a três vezes a renda mensal dos participantes. Entre outras conclusões, este estudo revelou significativa convergência de resultados entre tratamentos com ou sem incentivos, quando se analisavam decisões associadas à luz da Teoria dos Prospectos.

No caso desta pesquisa, as situações e tratamentos foram adaptadas, para corresponderem a ofertas no segmento de telefonia móvel. As questões originais das pesquisas de Kahneman e Tversky (1979) e Tversky e Kahneman (1981) foram então utilizadas na elaboração das questões a serem 
aplicadas no experimento e convertidas para representar as condições que se objetivou analisar. Executou-se a conversão das questões originais conforme a Figura 1. O Apêndice indica as questões originais dos estudos de Kahneman e Twersky e detalha os procedimentos para a construção do instrumento.

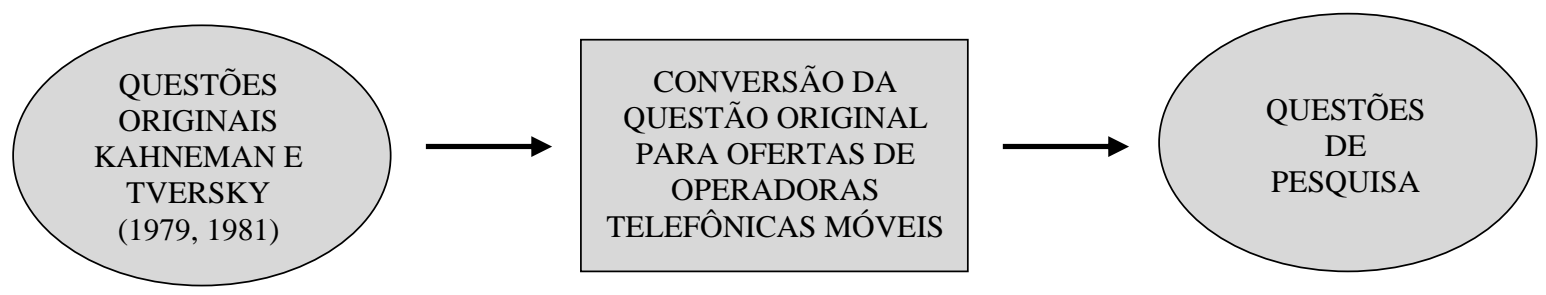

Figura 1. Diagrama de Criação das Questões de Pesquisa. Fonte: Elaboração dos autores.

A partir delas, foram geradas seis questões, de maneira a incluir variações de domínios e diferentes situações de framing, conforme Tabela 2.

Tabela 2

\section{Questões Aplicadas aos Indivíduos sob Análise}

Q01. Qual dos planos da operadora de telefonia móvel você escolheria?

A- Todas as ligações com $3 \%$ de desconto nas tarifas.

B- Quatro a cada cinco ligações terão desconto de $4 \%$ nas tarifas.

Q02. Qual plano de telefonia celular você prefere?

A- Todas as ligações com 3\% ao ano de reajuste nas tarifas.

B- Reajuste de $4 \%$ ao ano nas tarifas, e sorteio de 01 KIT-DESCONTO (isenção de reajustes) a cada cinco clientes.

Q03. Qual dos planos de telefonia celular abaixo, você prefere?

A- Todas as ligações com $3 \%$ de desconto nas tarifas.

B- Plano com celular incluso e quatro a cada cinco ligações com desconto de $4 \%$ nas tarifas.

Q04. Qual plano de telefonia celular você prefere?

A- Plano com celular incluso e todas as ligações com 3\% ao ano de reajuste nas tarifas.

B- Reajuste de $4 \%$ ao ano nas tarifas, e sorteio de 01 KIT-DESCONTO (isenção de reajustes) a cada cinco clientes..

Q05. Você foi a uma loja comprar um celular que custa $R \$ 324,00$, e nesta loja o vendedor lhe informa que o mesmo celular está sendo oferecido, em promoção, com desconto de $R \$ 13,00 \mathrm{em}$ outra loja rede, que fica a 20 minutos de carro dali. Você iria até esta outra loja para participar desta promoção?

A- Sim

B- Não

Q06. Você foi a uma loja comprar um celular que custa $R \$ 27,00$, e nesta loja o vendedor lhe informa que o mesmo celular está sendo oferecido, em promoção, com desconto de $R \$ 13,00 \mathrm{em}$ outra loja rede, que fica a 20 minutos de carro dali. Você iria até esta outra loja para participar desta promoção?

A- Sim

B- Não

Fonte: Elaboração dos autores. 
As questões foram validadas quanto à adequada transposição do estudo original por especialistas na área de Psicologia Comportamental fora da equipe de pesquisa. As questões 1 e 3 identificam as preferências dos decisores no domínio dos ganhos, enquanto as questões 2 e 4 se referem às preferências no domínio das perdas. A diferença entre o bloco de questões 1 e 2 em relação ao bloco 3 e 4 refere-se a aspectos situacionais que se apresentam para o decisor, ou seja, diferentes situações de framing. $\mathrm{O}$ mesmo se refere às questões 5 e 6.

Participantes. As questões foram aplicadas a 258 alunos distribuídos em quatro turmas de alunos de uma universidade de São Paulo. As turmas foram escolhidas aleatoriamente. A seleção de vários grupos de universitários para a participação desta pesquisa se justifica por apresentarem características socioeconômicas de idade, renda (Intituto Brasileiro de Geografia e Estatística [IBGE], 2009), consumo (Henz, 2003) e uso em minutos (Teleco, 2009), compatíveis com a população brasileira (Teleco, 2009). O tamanho dos grupos foi dimensionado objetivando a generalização posterior, assumindo-se uma distribuição binomial, cujos parâmetros iniciais foram obtidos por préamostragem e re-validados posteriormente (Bussab \& Morettin, 2002).

Alguns dados demográficos são sinteticamente apresentados a seguir. Em todos os itens da Tabela 3, as curvas de distribuição dos dados, as curvas de distribuição normal resultaram em curvas assimétricas positivas; portanto a mediana serve como medida mais robusta para a análise das informações, ao invés da média.

Tabela 3

\section{Dados da Amostra}

\begin{tabular}{lccc}
\hline Variável & Média & DP & Mediana \\
\hline Idade (anos) & 22,2 & 3,45 & 21 \\
Consumo Financeiro (R\$) & 66,7 & 58,8 & 50 \\
Consumo (Minutos) & 178 & 273 & 100 \\
Tempo com a operadora (meses) & 36,5 & 27,9 & 36 \\
\hline
\end{tabular}

Em relação ao gênero, 56,75\% dos respondentes são do sexo feminino e $43,25 \%$ do sexo feminino. A maior parte dos respondentes possui emprego (85,60\%), seguido por respondentes que estão desempregados $(8,60 \%)$ e respondentes que possuem funções profissionais autônomas $(5,60 \%)$. Embora não se possa assumir que a amostra pesquisada reflita, integralmente, o comportamento econômico da população brasileira, o indicador taxa de desocupação ou índice de desemprego da amostra alcançou ordem próxima da realidade brasileira: segundo pesquisa do IBGE, em agosto de 2009, a taxa de desocupação de 06 regiões metropolitanas foi 8,1\% (IBGE, 2009).

A renda domiciliar é a questão com maior número de dados omissos entre as variáveis de caracterização da amostra, pois algumas pessoas não se sentem confortáveis em divulgar esta informação. Assim, dos 258 entrevistados, apenas 248 responderam à questão. Do total, 71,84\% têm renda domiciliar mensal maior do que seis salários mínimos; 13,47\% têm renda superior a 20 salários mínimos.

A faixa de gasto (ou consumo) mensal com o telefone celular pode ser considerada um proxy para o volume de uso do serviço de telefonia celular, conforme executivos do setor. O conceito de ARPU (Average Revenue Per Unit) é utilizado nesta indústria e representa a média de gastos (expressa em R\$) de um usuário, dentro de um período de tempo, normalmente três meses (Henz, 2003).

De acordo com Informações de consumo da telefonia móvel brasileira (Teleco, 2009), verificase que o consumo dos universitários que participaram da pesquisa é superior ao da população brasileira. Estes números podem corroborar a relevância dos universitários neste setor da economia, conforme levantamento citado no início deste capítulo (Romano, 2008). 
A maioria dos respondentes $(63,49 \%)$ optou por se relacionar com a operadora por meio de um plano pré-pago de serviços, enquanto outra parte $(33,33 \%)$ dos respondentes possui plano pós-pago de telefonia e uma minoria dos respondentes $(3,17 \%)$ utiliza somente o telefone celular proveniente da empresa que em que trabalha.

A amostra pesquisada possui diferenças razoáveis em relação à opção de plano de telefonia móvel, pois a porcentagem da população brasileira que aderiu a planos pré-pagos possui valor de 82,21\%, em setembro de 2.009 (Teleco, 2009), enquanto nesta pesquisa, foram cerca de 63, 5\%.

A diferença na aquisição de planos pós-pagos, comparados com a população brasileira, também pode ser sinalizada como uma demonstração de maior poder aquisitivo, vista a capacidade de compromisso do gasto financeiro com a operadora de telefonia móvel.

Questionados sobre a origem do celular, a maioria dos respondentes $(61,20 \%)$ informou que adquiriu o celular com recursos próprios.

A representatividade do grupo foi aferida com base em dados da pesquisa Perfil do Consumidor Brasileiro de Telefonia Celular, de 2006, que indica que o Estado de São Paulo concentra o maior número de linhas móveis. A maioria dos compradores de telefone pós-pago (42\%) possui nível superior completo ou incompleto (Alves, 2006). Do total de consumo brasileiro, correspondente a R\$ 194 bilhões anuais, somente os universitários movimentam e influenciam R 76 bilhões anuais (cerca de $40 \%$ do consumo anual total).

\section{Técnicas de Análise de Dados}

As respostas das questões de pesquisa ligadas às teorias de decisão proporcionam respostas que podem ser classificadas como nominais. Em geral, este tipo de variáveis requer que a análise seja conduzida por meio de testes estatísticos Qui-quadrado e suas variantes, baseadas em frequencias de respostas. Esse tipo de técnica é largamente aplicado em campos como Medicina e Psicologia, onde é amplo o uso desenhos de pesquisa experimentais e quasi-experimentais, situações em que a proporção entre grupos é usada como medida do efeitos por diferenciar indivíduos que foram aleatoriamente submetidos a diferentes níveis de tratamentos e placebos, mediante diversos níveis de controle de outras causas possíveis (Agresti, 2002; Sproull, 2002). seguir.

Neste estudo, utilizamos vários testes de independência, conforme brevemente descritos a

Embora o teste do Qui-quadrado possa identificar se as variáveis são estatisticamente independentes, este teste não fornece eventuais formas de relação entre as variáveis; portanto, para tornar as análises e conclusões dos dados mais consistentes, serão calculados testes de associação entre as variáveis das questões de pesquisa, após a descrição do teste da taxa de verossimilhança do Quiquadrado (Reynolds, 1984).

O teste da taxa de verossimilhança do Qui-quadrado ( $\mathrm{L}^{2}$ ) é um teste alternativo para verificar a independência entre as variáveis de uma determinada tabela. Embora o cálculo deste teste seja diferente do cálculo do teste Qui-quadrado, a interpretação dos seus resultados é a mesma para ambos os testes (Agresti, 2002).

Para compensar superestimativas do valor do Qui-quadrado para tabelas de dupla entrada, usase a Correção de Yates de continuidade. Sua interpretação é idêntica aos testes Qui-Quadrado e L² (Agresti, 2002).

Já a estatística Log-odds é uma medida de associação entre as variáveis que possuem valores no intervalo entre $-\infty$ a $+\infty$, onde a definição relacionada ao valor $-\infty$ indica associação negativa; valor 
nulo significa independência entre as variáveis e $+\infty$ associação positiva entre as variáveis. Esta medida proporciona melhor interpretação a respeito da associação das variáveis (Reynolds, 1984).

$\mathrm{O} Q$ de Yule é um teste função da medida de associação odds ratio e conceituada como uma medida geral para pesquisas que envolvem a análise da associação entre variáveis ordinais. Seu resultado poderá estar contido no intervalo numérico entre -1 a +1 , onde -1 significa associação negativa, 0 significa independência e o valor +1 é interpretado como associação positiva das variáveis (Reynolds, 1984).

Em contrapartida, o Phi-quadrado ( $\left.\phi^{2}\right)$ é função da medida de associação odds ratio e seu valor poderá estar contido no intervalo numérico entre 0 a +1 , onde 0 significa que as variáveis são estatisticamente independentes e o valor +1 é interpretado como associação perfeita das variáveis (Reynolds, 1984).

Toda a operacionalização dos testes foi realizada usando o software MINITAB, versão 14 e planilha Excel 2007.

\section{Resultados e Discussão}

Para testar a existência dos fenômenos descritos nas teorias de decisão dos autores Kahneman e Tversky (1979) e Tversky e Kahneman (1981), foi necessário analisar os resultados das questões ligadas aos fenômenos decisórios, que se referem aos efeitos reflexão, certeza e framing por meio dos testes estatísticos selecionados na metodologia. A seguir, são apresentados os resultados obtidos e respectivas discussões.

\section{Efeito certeza e reflexão}

Para estes fenômenos decisórios, é esperado que os indivíduos apresentem um comportamento de aversão ao risco, quando no domínio dos ganhos e preferência pelo risco no domínio das perdas (Kahneman \& Tversky, 1979). Sendo assim, foram selecionados os resultados da questão 1, cujo conteúdo permite verificar o comportamento decisório sob risco no domínio dos ganhos; e a questão 2, que permite verificar o comportamento decisório sob risco no domínio das perdas. Para analisar se o comportamento decisório sob risco realmente é diferente entre os domínios dos ganhos e das perdas, foi considerada a frequência de respostas dadas a cada item nas questões 1 e 2, entre os quesitos sem risco e com risco.

Os resultados são apresentados na Tabela 4. Inicialmente, podemos observar que, no domínio dos ganhos (questão 1), uma significativa maioria prefere a alternativa sem risco (93\%), em relação à alternativa com risco (7\%), comprovando a ocorrência do efeito certeza, exatamente como as pesquisas de Kahneman e Tversky (1979) haviam proposto.

Tabela 4

Decisões com Opções Certas e Prováveis no Domínio dos Ganhos e Perdas

\begin{tabular}{lcc}
\hline \multicolumn{1}{c}{ Fator de influência } & Sem risco (A) & Com risco (B) \\
\hline Efeito certeza (domínio dos ganhos) & $\mathbf{9 3 \%}$ & $\mathbf{7 \%}$ \\
Efeito reflexão (domínio das perdas) & $\mathbf{7 8 \%}$ & $\mathbf{2 2 \%}$ \\
\hline
\end{tabular}

Fonte: Elaboração dos autores.

Em relação ao domínio das perdas, entretanto, os resultados são dúbios. A proporção de preferência sem risco (78\%) ainda é maior que com risco (22\%). Entretanto a proporção é menor que 
no caso anterior, indicando uma tendência de maior valorização da alternativa com risco do que no domínio dos ganhos.

Para analisar mais detalhadamente se a mudança de domínio de ganhos para perdas explica efetivamente a diferença de proporções $93 / 7$ para $78 / 22$, executamos um teste de comparação entre as frequências dos dois grupos. Os resultados são apresentados na Tabela 5.

Tabela 5

Testes Estatísticos - Efeito Certeza e Reflexão nas Ofertas de Telefonia Móvel

\begin{tabular}{cccccc|ccc}
\hline \multicolumn{5}{c|}{ Testes de independência } & \multicolumn{3}{c}{ Testes de associação } \\
\hline $\mathbf{X}^{\mathbf{2}}$ & $\begin{array}{c}\mathbf{p} \text {-valor } \\
\left(\mathbf{X}^{2} \mathbf{)}\right.\end{array}$ & $\mathbf{L}^{2}$ & $\begin{array}{c}\mathbf{p} \text {-valor } \\
\left(\mathbf{L}^{2}\right)\end{array}$ & Yates & p-valor & $\phi^{2}$ & Q de Yule & Log odds \\
\hline 10,57 & 0,00 & 10,99 & 0,00 & 9,43 & 0,00 & 0,04 & 0,56 & 1,27 \\
$\begin{array}{c}\text { Há } \\
\text { diferenças }\end{array}$ & Significante & $\begin{array}{c}\text { Há } \\
\text { diferenças }\end{array}$ & Significante & $\begin{array}{c}\text { Há } \\
\text { diferenças }\end{array}$ & Significante & Independência & Incerto & Independência \\
\hline
\end{tabular}

Fonte: Elaboração dos autores.

Pode-se afirmar, com base nos resultados dos três testes de independência, que os dois grupos de respondentes podem ser considerados diferentes entre si, uma vez que em todos os casos a significância resultante dos testes de independência foi abaixo de 1 \% (p-valor < 0,01) (Agresti, 2002; Reynolds, 1984).

Já os resultados dos testes de associação indicam que os cruzamentos dos resultados das questões podem ser considerados como estatisticamente independentes e não há associação entre estes tratamentos (Agresti, 2002; Bishop, Fienberg, \& Holland, 1975; Reynolds, 1984). Percebe-se que a medida Q de Yule não demonstra, neste caso, se existe a associação entre as variáveis; mas, de acordo com Bishop, Fienberg e Holland (1975), esta medida pode ter seu resultado superestimado e, portanto, consideramos os resultados obtidos pelo phi-quadrado e log-odds como aceitáveis.

Em outras palavras, podemos concluir que ocorreu inversão das decisões sob risco entre o domínio de perdas em relação à posição inicial no domínio dos ganhos, ou seja, os indivíduos apresentaram preferências dependentes do tratamento, no caso a mudança de domínios, o que corrobora os resultados do estudo de Kahneman e Tversky (1979). Portanto tal inversão indica a existência destes fenômenos, quando aplicado ao setor de telefonia móvel e, nesse caso, encontramos suporte à Hipótese 1.

Embora a maioria dos respondentes não manifestasse comportamento decisório de preferência ao risco no domínio das perdas, notam-se diferenças significativas entre as frequências observadas e esperadas das respostas entre os dois tipos de efeitos estudados, vistos os resultados dos testes de independência para estas questões. Entendemos essas diferenças e resultados como evidência suficiente para dar suporte à Hipótese 2.

Por conseguinte, dadas as frequências observadas dos resultados decisórios no domínio das perdas, revela-se aqui uma importante descoberta nesta pesquisa: a hipótese de que possam existir limites à percepção individual para o gatilhamento de certos fenômenos decisórios. Por estes resultados, é possível supor que haveria limites à existência dos axiomas decisórios no comportamento dos indivíduos e que a transposição destes poderia ser determinada por diversas informações das ofertas ou outros fatores ligados à percepção dos indivíduos, tais como os valores de aquisição de um determinado bem ou percentuais de descontos apresentados na oferta.

Tal explicação converge com os últimos avanços na Teoria dos Prospectos que originaram no campo teórico da economia comportamental seus novos desdobramentos e a proposição da denominada Teoria dos Prospectos Acumulativa (TPA) (Tversky \& Kahneman, 1992), que continua 
suscitando discussões na academia. Embora estas evidências tenham surgido nesta etapa, a TPA não é o foco desta pesquisa.

\section{Efeito certeza e reflexão com subsídio de aparelhos celulares}

Para analisar se o subsídio de aparelhos celulares, recurso promocional presente em certas ofertas de operadoras de telefonia móvel, poderia influir nos efeitos certeza e reflexão observados anteriormente, foram introduzidas no estudo modificações na apresentação de alternativas, favorecendo aquelas que seriam menos preferidas, de acordo com o que preconiza a TP. Essa adaptação foi considerada adequada pelos pesquisadores, respeitado o pressuposto inicial da pesquisa de se procurar a replicação dos estudos originais, mas levando em conta os aspectos e características das ofertas desse segmento. Dessa variante das questões 1 e 2 , surgiram as questões 3 e 4 . Os resultados das frequências observadas para essas questões são apresentados na Tabela 6 .

Tabela 6

Decisões das Ofertas com Opções Certas e Prováveis no Domínio dos Ganhos e Perdas com Subsídio de Celulares

\begin{tabular}{lcc}
\hline \multicolumn{1}{c}{ Fator de influência } & Sem risco (A) & Com risco (B) \\
\hline $\begin{array}{l}\text { Efeito certeza (domínio dos ganhos) incluído } \\
\text { subsídio de aparelho celular }\end{array}$ & $\mathbf{7 4 \%}$ & $\mathbf{2 6} \%$ \\
$\begin{array}{l}\text { Efeito reflexão (domínio perdas) incluído subsídio de } \\
\text { aparelho celular }\end{array}$ & $\mathbf{8 2 \%}$ & $\mathbf{1 8 \%}$ \\
\hline
\end{tabular}

Fonte: Elaboração dos autores.

A análise da influência da inclusão do subsídio como variações de oferta, no domínio dos ganhos, foi feita por meio de comparações entre as frequências de respostas dadas para a questão 1, que contempla o domínio dos ganhos e não contém o subsídio nas ofertas, e da questão 3, que o contém. Já para a análise no domínio das perdas, foi feita a análise por comparações entre as frequências de respostas dadas para a questão 2, que contempla o domínio das perdas e não contém o subsídio nas ofertas, e da questão 4, que o contém.

\section{Influência do subsidio sobre efeito certeza no domínio dos ganhos}

De acordo com a Tabela 7, verificam-se diferenças significativas entre as frequências observadas e esperadas das respostas entre as questões 1 e 3 , já que os resultados dos testes de independência indicam que se trata de grupos diferentes (significante a 1\%). Além disso, também indicam que a diferença de tratamentos nos questionários com a inclusão do subsídio de aparelho celular pode ser considerada como principal aspecto motivador para a composição das decisões dos respondentes.

Tabela 7

Testes Estatísticos - Efeito Certeza com Subsídio no Domínio dos Ganhos

\begin{tabular}{cccccc|ccc}
\hline \multicolumn{7}{c|}{ Testes de independência } & \multicolumn{3}{c}{ Testes de associação } \\
\hline $\mathbf{X}^{\mathbf{2}}$ & $\begin{array}{c}\mathbf{p} \text {-valor } \\
\left(\mathbf{X}^{2} \mathbf{)}\right.\end{array}$ & $\mathbf{L}^{2}$ & $\begin{array}{c}\mathbf{p} \text {-valor } \\
\left(\mathbf{L}^{2}\right)\end{array}$ & Yates & $\mathbf{p}$-valor & $\phi^{2}$ & Q de Yule & Log odds \\
\hline 14,50 & 0,00 & 15,20 & 0,00 & 13,21 & 0,00 & 0,06 & 0,62 & 1,46 \\
$\begin{array}{c}\text { Há } \\
\text { diferenças }\end{array}$ & Significante & $\begin{array}{c}\text { Há } \\
\text { diferenças }\end{array}$ & Significante & $\begin{array}{c}\text { Há } \\
\text { diferenças }\end{array}$ & Significante & Independência & Incerto & Independência \\
\hline
\end{tabular}

Fonte: Elaboração dos autores. 
De forma semelhante à análise e interpretação dos testes de associação e independência no efeito certeza e reflexão (item 1), conclui-se que se pode afirmar que os respondentes alteraram suas decisões por meio da influência do subsídio de aparelhos celulares em uma das ofertas. O estudo mostra forte suporte à Hipótese 4a, pois esta influência pode causar uma reversão do resultado esperado, com a capacidade de inverter o axioma decisório descrito nos estudos de Kahneman e Tversky (1979).

Em outras palavras, apresenta-se uma manifestação de comportamento decisório de aversão ao risco no domínio dos ganhos. Outra possível interpretação deste resultado seria a consideração, pelo respondente, do aparelho subsidiado como um ganho certo na oferta e assim preferir esta opção, conservando a aversão ao risco no domínio dos ganhos, muito embora a oferta apresente determinado componente de risco à tarifação das ligações.

Embora contraditória, e talvez discutível, a negação deste axioma, tendo em vista a importância científica e expressiva validação dos estudos de Kahneman e Tversky, entende-se que a inclusão do subsídio se manifesta como um componente com influência significativa nas decisões dos indivíduos, quando confrontados com as ofertas das operadoras.

Tal recurso de subsídio de aparelhos se encontra à disposição das operadoras de telefonia para, entre outros fins, tornarem mais atrativas suas ofertas aos clientes, perante a sua concorrência. Convém lembrar que a inclusão do subsídio ocorreu de maneira assimétrica entre as alternativas de uma mesma questão, modificando completamente o framing de decisão.

\section{Influência do subsidio sobre o efeito reflexão no domínio das perdas}

Procedimentos semelhantes foram implementados para a análise do efeito reflexão, no domínio das perdas, sob a influência de subsídio de celulares.

Neste caso e de acordo com a Tabela 8, verifica-se baixa diferença entre as frequências das respostas dos dois tipos de questionário. De maneira semelhante à análise e interpretação dos testes de associação e independência no efeito certeza (item 1 e 2), conclui-se que não se poderia afirmar que os respondentes alteraram suas decisões por meio da influência do subsídio de aparelhos celulares em uma das ofertas apresentadas. Existem restrições à negação, no entanto, da influência do subsídio de acordo com os resultados dos testes apresentados. O estudo apresenta evidências moderadas a favor do suporte da Hipótese $\mathbf{4 b}$.

Tabela 8

Testes Estatísticos - Efeito Reflexão com Subsídio no Domínio das Perdas

\begin{tabular}{cccccc|ccc}
\hline \multicolumn{7}{c|}{ Testes de independência } & \multicolumn{3}{c}{ Testes de associação } \\
\hline $\mathbf{X}^{2}$ & $\begin{array}{c}\mathbf{p} \text {-valor } \\
\left(\mathbf{X}^{2}\right)\end{array}$ & $\mathbf{L}^{2}$ & $\begin{array}{c}\mathbf{p} \text {-valor } \\
\left(\mathbf{L}^{2}\right)\end{array}$ & Yates & $\mathbf{p}$-valor & $\phi^{2}$ & Q de Yule & Log odds \\
\hline 0,64 & 0,42 & 0,64 & 0,42 & 0,41 & 0,52 & 0,00 & $-0,13$ & $-0,26$ \\
$\begin{array}{c}\text { Diferença } \\
\text { baixa }\end{array}$ & $\begin{array}{c}\text { Não é } \\
\text { significante }\end{array}$ & $\begin{array}{c}\text { Diferença } \\
\text { baixa }\end{array}$ & $\begin{array}{c}\text { Não é } \\
\text { significante }\end{array}$ & $\begin{array}{c}\text { Diferença } \\
\text { baixa }\end{array}$ & $\begin{array}{c}\text { Não é } \\
\text { significante }\end{array}$ & $\begin{array}{c}\text { Independência } \\
\text { Independência }\end{array}$ & Independência \\
\hline
\end{tabular}

Fonte: Elaboração dos autores.

Em resumo, nesta etapa, para os testes relativos aos efeitos certeza e reflexão, conclui-se que há suporte à Hipótese 1 e Hipótese 2. Adicionalmente, foi encontrada evidência que favorece uma explicação sobre a existência de limites na confirmação dos axiomas da TP que pudessem gatilhar esta manifestação.

Também foi possível identificar que existe influência do subsídio de celulares, considerado um fator de influência relevante nas decisões dos indivíduos e que possibilitaria a alteração, ainda que 
superficial, de comportamento decisório, em comparação a outras ofertas. O estudo mostra que, no domínio dos ganhos, a influência do subsídio de aparelhos é capaz de reverter a decisão, com forte suporte à Hipótese 4a. Já no domínio das perdas, o estudo apresenta resultados dúbios, com moderado suporte à Hipótese $\mathbf{4 b}$.

\section{Efeito framing por referências de preços}

Em relação ao efeito framing, o experimento consiste em expor os decisores a situações em que os valores de ganhos são iguais, mas que são apresentados de forma diferente, gerando uma referência artificial que se supõe influente na decisão, segundo os axiomas da TP. Isso é feito nas questões 5 e 6 que, diferentemente das demais, não foram respondidas pelos mesmos indivíduos, já que a lógica das questões poderia ser identificada, caso os respondentes fossem expostos a ambas as situações. Foram efetuadas análises estatísticas e foi possível assegurar que os grupos podem ser considerados previamente homogêneos. Os resultados são apresentados na Tabela 9.

Tabela 9

Decisões das Ofertas com Descontos nos Preços e Alteração do Valor do Bem de Consumo como Referência

\begin{tabular}{lcc}
\hline \multicolumn{1}{c}{ Fator de influência } & Opção ‘Sim’ (A) & Opção ‘Não’ (B) \\
\hline Efeito Framing (maior valor de referência) & $\mathbf{6 9} \%$ & $\mathbf{3 1} \%$ \\
Efeito Framing (menor valor de referência) & $\mathbf{8 1 ~ \%}$ & $\mathbf{1 9} \%$ \\
\hline
\end{tabular}

Fonte: Elaboração dos autores.

De acordo com a Tabela 10, verificam-se diferenças significativas entre as frequências observadas das respostas entre as duas questões. A interpretação dos testes estatísticos apresentados indica que a diferença de tratamentos nos questionários com a manipulação do conteúdo das ofertas para manifestação do efeito framing pode ser considerado como um componente influenciador na composição das decisões dos respondentes. Semelhante à análise e interpretação dos testes de associação e independência para o estudo do efeito certeza e reflexão (item 1), conclui-se que se pode afirmar que os respondentes alteraram suas decisões por meio da influência do efeito framing. Esses dados permitem sustentar a Hipótese 3.

Tabela 10

Testes Estatísticos - Decisões das Ofertas com Descontos nos Preços e Alteração do Valor do Bem de Consumo como Referência

\begin{tabular}{cccccc|ccc}
\hline \multicolumn{5}{c|}{ Testes de independência } & \multicolumn{3}{c}{ Testes de associação } \\
\hline $\mathbf{X}^{\mathbf{2}}$ & $\mathbf{p}$-valor $\left.\mathbf{X}^{\mathbf{2}}\right)$ & $\mathbf{L}^{2}$ & $\mathbf{p}$-valor $\left.\mathbf{L}^{2}\right)$ & Yates & $\mathbf{p}$-valor & $\phi^{2}$ & Q de Yule & Log odds \\
\hline 4,93 & 0,03 & 4,97 & 0,03 & 4,30 & 0,04 & 0,02 & $-0,32$ & $-0,67$ \\
$\begin{array}{c}\text { Há } \\
\text { diferenças }\end{array}$ & Significante & $\begin{array}{c}\text { Há } \\
\text { diferenças }\end{array}$ & Significante & $\begin{array}{c}\text { Há } \\
\text { diferenças }\end{array}$ & $\begin{array}{c}\text { Significante, } \\
\text { com } \\
\text { restrições }\end{array}$ & Independência & Incerto & Independência \\
\hline
\end{tabular}

Fonte: Elaboração dos autores.

Tversky e Kahneman (1981) definiram que as pessoas tendem a considerar, preferencialmente, ganhos e perdas relativas ao invés de ganhos e perdas absolutas. Assim, os R $\$ 13,00$ parecem mais atrativos na questão 6 do que na questão 5. De acordo com esta análise, pode-se afirmar respondentes alteraram suas decisões, considerando os ganhos relativos ao invés de ganhos absolutos. Desta maneira, corrobora-se a influência do efeito framing nas decisões por meio das ofertas de telefonia 
móvel baseadas em referências de preço o que, converge com o estudo de Tversky e Kahneman (1981).

\section{Conclusões}

De acordo com o referencial teórico, estudos têm demonstrado a existência de axiomas nas decisões; as decisões se apresentam como inconsistentes com os princípios da teoria da utilidade esperada. Desta maneira, vários estudos foram desenvolvidos, sugerindo um possível desvio ou limitação da racionalidade e inclusão de outros aspectos do comportamento humano no processo de decisão sob risco (Kahneman \& Tversky, 1974, 1979; Simon, 1987; Simonson \& Tversky, 1992; Tversky \& Kahneman, 1981). Esta pesquisa procurou avaliar possibilidade de aplicação desses conceitos no setor de telefonia móvel. Foram considerados os axiomas decisórios indicados nos estudos de Kahneman e Tversky (1979) e Tversky e Kahneman (1981), além da inclusão de determinadas formas de apresentação de ofertas específicas do setor estudado, incluindo o subsídio de aparelhos celulares, o que permitiu a observação dos resultados e efeitos destas inclusões.

Para a criação e aplicação das questões de pesquisa, foi selecionado o setor de telefonia móvel, por conter diversas características que satisfazem as condições de aplicabilidade deste estudo. Entre outras características que podem ser citadas, inclui-se a oferta de subsídios de aparelhos celulares com recursos específicos, sendo a concessão deste subsídio geralmente condicionado à manutenção do relacionamento comercial com a operadora de telefonia. Além disso, convém ser mencionada a relevância do setor relativo à economia brasileira; além do crescimento expressivo de clientes nos últimos anos, o que justificaria a geração de estudos científicos que analisem, entre outras áreas, há os impactos das operações e estratégias dos fornecedores que atuam no setor, assim como aspectos decisórios dos clientes e os respectivos reflexos destas decisões.

A primeira conclusão a que se chega, a partir deste estudo, refere-se ao êxito na utilização do modelo de pesquisa criado para o estudo de comportamentos e fenômenos decisórios na aquisição de tecnologias; sejam observadas as limitações de generalização da pesquisa. Neste sentido, verifica-se a validade de construto pela efetiva aplicabilidade das questões de pesquisa, sob diferentes formas de apresentação das ofertas de telefonia móvel, para a corroboração de determinados fenômenos das teorias comportamentais de decisão. Além disto, o processo de criação e conversão das questões originais das teorias de Kahneman e Tversky nas questões de pesquisa geradas se mostrou satisfatório, permitindo o alcance dos objetivos deste estudo.

Sobre os testes estatísticos apresentados, o cálculo de três testes estatísticos dos dados categóricos para análises de independência e associação permitiu conclusões confiáveis sobre os resultados, principalmente nos casos de alguns testes apresentarem valores dúbios.

Este estudo conseguiu replicar algumas conclusões obtidas por Kahneman e Tversky sobre os fenômenos de decisão sob risco e o efeito framing; ficou evidenciado que estas teorias de decisão podem ser aplicadas no estudo de decisões sobre a aquisição de produtos na área de tecnologia, em especial no segmento de telefonia móvel. Em outras palavras, a pesquisa permitiu corroborar a existência de fatores de influência do comportamento decisório associados aos fenômenos de aversão ao risco, sob domínio dos ganhos, e o efeito framing, relacionado à consideração dos domínios dos ganhos e perdas. Assim, entende-se que os fatores de influência do comportamento decisório podem agir, entre outros fatores, diretamente no processo de escolha dos indivíduos sobre qual oferta da operadora de telefonia seria mais interessante aos contratantes.

Também foi constatado que os indivíduos apresentam determinados comportamentos decisórios, que podem violar os princípios da Teoria da Utilidade Esperada. Neste sentido, uma implicação prática consiste em observar que as operadoras de telefonia móvel podem valer-se de diversas formas de apresentação de ofertas, que poderiam auxiliá-las na aceitação de suas propostas comerciais aos 
clientes, uma vez que as propostas poderiam ser consideradas a partir de diferentes perspectivas pelo contratante. Congruente com esta última afirmação é revelador saber que a operadora de telefonia móvel possui, em tese, condições de manipulação da percepção da decisão do cliente em seu favor, dependendo dos fatores de influência do comportamento decisório que esta organização utilizaria para embasar e compor as suas ofertas.

No entanto, foi levantada a suspeita, com base em evidências, da existência de possíveis limites no estudo do risco sob domínio das perdas e que, por sua vez, podem tratar-se de variantes ainda não estudadas, ou até mesmo de novos preceitos associados às teorias de decisão. Sugere-se que, em estudos futuros, possa ser verificado se os fenômenos decisórios estudados se manifestam dentro de determinadas condições, ou limites, implícitos nas possibilidades de escolhas, submetidas à decisão dos indivíduos. Até onde temos conhecimento, não há estudos publicados na academia que foquem este tema no campo estudado.

Por sua vez, a influência do subsídio de celulares mostrou-se relevante, ao promover a reversão do comportamento decisório de um determinado fenômeno: a aversão ao risco, no domínio dos ganhos. O subsídio de aparelhos celulares aos clientes pelas operadoras de telefonia é prática comercial comum no Brasil e em outros países; percebe-se então a potencialidade de que o subsídio de celulares possui para não somente alterar, mas reverter decisões dos participantes, a tal ponto de reduzir a manifestação dos axiomas descritos na Teoria das Perspectivas. Assim, a operadora de telefonia, efetivamente, conta com o subsídio de celulares como outro recurso para manipulação da decisão do cliente, além da possibilidade da exploração de determinados fenômenos dos comportamentos decisórios na criação de suas ofertas.

Ressalta-se que nas ofertas apresentadas com subsídio de celulares não foram expostas informações adicionais a estas ofertas, como as seguintes: marca dos aparelhos, recursos tecnológicos inclusos no telefone, serviços e facilidades que a utilização destes aparelhos proporciona ao usuário, publicidade a respeito do status pessoal que o usuário obteria com a aquisição de um aparelho celular de última geração, entre outros benefícios. Infere-se que as ofertas com a apresentação dessas informações sobre o celular subsidiado podem atrair um número possivelmente maior de clientes, que podem ser fidelizados às operadoras de telefonia; elas, portanto, poderiam aumentar seu poder de monopólio.

A respeito das contribuições originadas desta pesquisa, podem ser citados os resultados e informações que podem auxiliar decisões dos órgãos reguladores do setor, nas suas regulamentações; considere-se a capacidade de manipulação das decisões dos clientes, por meio de ofertas das operadoras de telefonia, dadas as diferentes apresentações das propostas comerciais que podem ser elaboradas. Entre outros interesses, os órgãos reguladores buscam ampliar a competitividade e a concorrência do setor e, portanto, é relevante que sejam feitos estudos científicos que possam auxiliar os órgãos reguladores a prevenir as operadoras de telefonia de atuar contra os interesses públicos e auxiliar a identificação de possíveis estratégias comerciais monopolistas que podem ser implementadas pelas operadoras, para reter seus clientes por influências nas decisões e manipulação de suas preferências individuais, reduzindo a eficiência de mercado.

Já do ponto de vista do cliente, esta pesquisa pode possibilitar melhor entendimento do funcionamento das eventuais ofertas das operadoras de telefonia, em função da melhora de sua percepção contra estas ofertas comerciais, que objetivem sua retenção à operadora, aprimorando a sua capacidade de decisão.

Do ponto de vista gerencial, este estudo revela alguns mecanismos que podem ser mais efetivos na influência do processo de decisão dos clientes, além de apresentar estratégias de vendas que podem ser utilizadas em campanhas publicitárias e que permitem facilitar a aprovação das suas ofertas pelos clientes.

Importa mencionar as limitações deste estudo; por exemplo, a generalização dos resultados desta amostra à população de usuários de telefonia móvel, uma vez que os dados do grupo tenham sido 
demograficamente avaliados e seu perfil corresponda ao de uma parcela significativa dos usuários brasileiros.

Sugere-se ainda, em estudos futuros, a aplicação deste modelo de pesquisa em outros estudos de decisão de investimentos em tecnologia, cujos valores de aquisições largamente extrapolam as cifras consideradas neste estudo, o que pode influir sobremaneira nas decisões.

\section{Artigo recebido em 21.02.2011. Aprovado em 13.09.2011.}

\section{Referências}

Agência Nacional de Telecomunicações. (2008). Telefonia móvel ultrapassa 140 milhões de assinantes. Recuperado em 8 dezembro, 2008, de http://www.anatel.gov.br/Portal/exibirPortalNoticias.do?acao=carregaNoticia\&codigo=16997

Agresti, A. (2002). Categorical data analysis. New York: John Wiley \& Sons.

Aldrighi, D. M., \& Milanez, D. Y. (2005). Finança comportamental e a hipótese dos mercados eficientes. Revista de Economia Contemporânea, 9(1), 41-72.

Alves, A. (2006). Quem são os usuários de celular. Recuperado em 17 dezembro, 2008, de http://www.aliceramos.com/view.asp?materia $=978$

Avila, M. G., \& Serpa, D. A. (2004). Percepção sobre preço e valor: um teste experimental. Revista de Administração de Empresas Eletrônica, 3(2). Recuperado de http://www.scielo.br/pdf/raeel/v3n2/v3n2a12.pdf. doi: 10.1590/S1676-56482004000200012

Bishop, Y. Y. M., Fienberg, S. E., \& Holland, P. W. (1975). Discrete multivariate analysis: theory and practice. Cambridge: MIT Press.

Brei, V. A., \& Rossi, C. A. (2005). Confiança, valor percebido e lealdade em trocas relacionais de serviço: um estudo com usuários de internet banking no brasil. Revista de Administração Contemporânea, 9(2), 145-168. doi: 10.1590/S1415-65552005000200008

Bussab, W. O., \& Morettin, P. A. (2002). Estatística básica. São Paulo: Editora Saraiva

Camerer, C. F. (1989). An experimental test of several generalized utility theories. Journal of Risk \& Uncertainty, 2(1), 61-104. doi: 10.1007/BF00055711

Chen, P.-Y., \& Hitt, L. M. (2002). Measuring switching costs and the determinants of customer retention in internet-enabled businesses: a study of the online borkerage industry. Information Systems Research, 13(3), 255-274. doi: 10.1287/isre.13.3.255.78

Christensen, C. M., Anthony, S. D., \& Roth, E. A. (2004). Seeing what's next: using the theories of innovation to predict industry change. Boston: Harvard Business School Publishing.

Cruz, L. B. (2004). Inovação tecnológica e vantagem competitiva no setor de telefonia móvel (Dissertação de mestrado). Universidade Federal do Rio Grande do Sul, Porto Alegre, RS, Brasil.

Espinoza, F. D. S., \& Larán, J. A. (2006). Consumidores satisfeitos, e então? Analisando a satisfação como antecedente da lealdade. Revista de Administração Contemporânea, 8(2), 51-70. doi: 10.1590/S1415-65552004000200004 
Favaretto, F. (2006). Influência da estrutura das informações nas decisões. Anais do Simpósio de Engenharia da Produção, Bauru, SP, Brasil, 13.

Henz, M. M. (2003). Programa de relacionamento viva claro: avaliação geral dos benefícios para empresa e clientes com base nas atitudes e comportamentos dos clientes (Tese de doutorado). Universidade Federal do Rio Grande do Sul, Porto Alegre, RS, Brasil.

Hsee, C. K. (1998). Less is better: when low-value options are valued more highly than high-value options. Journal of Behavioral Decision Making, 11(2), 107-121. doi: 10.1002/(SICI)10990771(199806)11:2<107::AID-BDM292>3.0.CO;2-Y

Instituto Brasileiro de Geografia e Estatística. (2009). Pesquisa mensal de emprego. Recuperado em $25 \quad$ outubro, 2009, de http://www.ibge.gov.br/home/estatistica/indicadores/trabalhoerendimento/pme_nova/pme_2009 09quadroSintetico.pdf

Kachelmeier, S. J., \& Shehata, M. (1992). Examining risks preferences under high monetary incentives: experimental evidence from the People's Republic of China. American Economic Review, 82(5), 1120-1141.

Kahneman, D., \& Tversky, A. (1974). Judgement under uncertainty: heuristics and biases. Science, 185(4157), 1124-1131. doi: 10.1126/science.185.4157.1124

Kahneman, D., \& Tversky, A. (1979). Prospect theory: an analysis of decision under risk. Econometrica, 47(2), 263-291. doi: 10.2307/1914185

Kalil, L. L., Melo, W. V., \& Schneider, D. D. G. (2006). O papel das heurísticas no julgamento e na tomada de decisão sob incerteza. Estudos de Psicologia, 23(2), 181-189. doi: 10.1590/S0103166X2006000200008

Loomes, G., \& Sugden, R. (1982). Regret theory: an alternative theory of rational choice under uncertainty. The Economic Journal, 92(368), 805-824. doi: 10.2307/2232669

Loural, C. D. A., \& Oliveira, R. C. D. (2005). Impacto da introdução de tecnologia de voz sobre IP no desempenho de operadoras tradicionais: uma simulação de cenários. Cadernos CPqD Tecnologia, 1(1), 155-179.

Mackenzie, M. L. (2004). Are managers rational actors? [Working paper]. Recuperado em 21 outubro, 2011, de http://www.dowling.edu/faculty/Mackenzie/docs/rational.pdf

Masuda, Y., \& Whang, S. (2006). On the optimality of fixed-up to tariff for telecommunications service. Information Systems Research, 17(3), 247-253. doi: 10.1287/isre.1060.0097

Maule, J., \& Villejoubert, G. (2007). What lies beneath: reframing framing effects. Thinking \& Reasoning, 13(1), 25-44. doi: 10.1080/13546780600872585

Milgrom, P., \& Roberts, J. (1992). Economics, organization and management. Upper Side River, NJ: Prentice Hall.

Neuman, J. von, \& Morgenstern, O. (1947). Theory of games and economic behaviour (2a ed.). Princeton: Princeton University Press.

Organization of Economic Cooperation and Development. (2003). OECD Communications Outlook [Folheto]. Paris: OECD Publishing.

Pablo, A. L., \& Sitkin, S. B. (1992). Reconceptualizing the determinants of risk behaviour. Academy of Management Review, 17(1), 9-38. doi: 10.2307/258646 
Reynolds, H. T. (1984). Analysis of nominal data: quantitative applications in the social sciences (2a ed.). Beverly Hills, CA: SAGE Publications.

Romano, C. (2008). Universitários: o novo alvo para fidelizar sua marca. Recuperado em 21 outubro, 2011, de http://www.portaleducacao.com.br/estetica/artigos/4486/universitarios-o-novo-alvopara-fidelizar-sua-marca

Sanchez, O. P., \& Albertin, A. L. (2009). A racionalidade limitada das decisões de investimento em tecnologia da informação. Revista de Administração de Empresas, 49(1), 86-106. doi: 10.1590/S0034-75902009000100010

Simon, H. (1987). Making management decisions: the role of intuition and emotion. The Academy of Management Executive, 1(1), 57-64. doi: 10.2307/4164720

Simon, H. (1991). Bounded rationality and organizational learning. Organization Science, 2(1), 125134. doi: $10.1287 /$ orsc.2.1.125

Simon, H., Dantzig, G. B., Hogarth, R., Plott, C. R., Raiffa, H., Schelling, T. C., Shepsle, K. A., Thaler, R., Tversky, A., \& Winter, S. (1987a). Decision making and problem solving. Interfaces, 17(5), 11-31.

Simonson, I., \& Tversky, A. (1992). Choice in context: tradeoff contrast and extremeness aversion. Journal of Marketing Research, 29(3), 281-295. doi: 10.2307/3172740

Smith, G. E., \& Nagle, T. T. (1995). Frames of reference and buyer's perception of price and value. California Management Review, 38(1), 98-116.

Sproull, N. L. (2002). Handbook of research methods. Folkestone: The Sacrecrow Press.

Teleco Informação e Serviços de Telecomunicações Ltda (2009). A queda do ARPU das operadoras de celular. Recuperado em 8 agosto, 2009, de http://www.teleco.com.br/comentario/com319.asp

Tversky, A., \& Kahneman, D. (1981). The framing of decisions and the psychology of choice. Science, 211(4481), 453-458. doi: 10.1126/science.7455683

Tversky, A., \& Kahneman, D. (1992). Advances in prospect theory: cumulative representation of uncertainty. Journal of Risk and Uncertainty, 5(4), 297-323. doi: 10.1007/BF00122574

Valor Econômico. (2009, junho 15). Perda de clientes é o maior risco para operadoras, aponta estudo. Jornal Valor Econômico, (2278).

Viard, V. B. (2007). Do switching costs make markets more or less competitive? The case of 800number portability. The RAND Journal of Economics, 38(1), 146-163. 


\section{APÊNDICE}

\section{Procedimento de Conversão para Criação do Instrumento}

\begin{tabular}{|c|c|}
\hline QUESTÃO ORIGINAL (a) & $\begin{array}{l}\text { PROCEDIMENTO DE } \\
\text { CONVERSÃO }\end{array}$ \\
\hline Qual das alternativas você escolhe? & \multirow{3}{*}{$\begin{array}{l}\text { dois componentes principais: o ganho } \\
\text { certo, e uma alternativa de risco de } 25 \% \\
\text { de obtenção de um benefício, } \\
\text { aproximadamente, quatro vezes maior } \\
\text { do que o ganho certo }\end{array}$} \\
\hline $\begin{array}{l}\text { A- } 100 \% \text { de chance de ganhar US\$ } \\
3.000,00 \text {; }\end{array}$ & \\
\hline $\begin{array}{l}\text { B- } 80 \% \text { chance de ganhar US\$ } 4.000,00 \\
\text { e } 20 \% \text { de chance de não ganhar nada }\end{array}$ & \\
\hline Qual das & \multirow{3}{*}{$\begin{array}{l}\text { três componentes principais: a perda } \\
\text { certa, uma alternativa de risco de } \\
80 \% \text { de perda de um valor } \\
\text { aproximadamente } 33 \% \text { da perda } \\
\text { certa, mas também com risco de } \\
20 \% \text { de chance de nenhuma perda } \\
\text { ao decisor. }\end{array}$} \\
\hline $\begin{array}{l}\text { A- } 100 \% \text { de chance de perder US\$ } \\
3.000,00\end{array}$ & \\
\hline $\begin{array}{l}\text { B- } 80 \% \text { de chance de perder US\$ } \\
4.000,00 \text { e } 20 \% \text { de chance de não } \\
\text { perder nada }\end{array}$ & \\
\hline
\end{tabular}

Idem 1

Idem 2

Você foi a uma loja comprar uma jaqueta que custa US\$125,00, e nesta loja o vendedor lhe informa que a mesma jaqueta, está custando US\$ 120,00 numa outra loja da mesma rede, que fica a 20 minutos de carro dali. Você iria até a outra loja adquirir esta jaqueta ?
A- Sim
B- Não

Kahneman e Tversky (1979) concluíram para sua questão original que a maioria das pessoas exibe um comportamento decisório de aversão ao risco no domínio dos ganhos.

Sendo assim, os pesquisadores optaram por inserir o subsídio na oferta com risco da questão 01 para verificar se haveriam diferenças de resultados neste tema, em função da característica do setor, fortemente operado por subsídios ao cliente

Kahneman e Tversky (1979) concluíram para sua questão original que a maioria das pessoas exibe um comportamento decisório de preferência pelo risco no domínio de perdas. Semelhante à questão 03, o pesquisador optou por inserir o subsídio na oferta da questão 02 que exibia perda certa, para verificar se haverá diferenças de resultados neste tema, em função da característica do setor, fortemente

Para a conversão desta questão destinada ao mercado de telefonia, o bem de consumo foi alterado para aparelho de celular. Em seguida, o valor atribuído ao celular foi calculado como 12 vezes o valor de receita média mensal por usuário de celular (ARPU), cujo valor aproximado chega a R \$324,00 no último trimestre de 2008 (TELECO, 2009). Foi atribuído o mesmo operado por subsídios ao cliente

\section{QUESTÃO FINAL}

Q01. Qual dos planos da operadora de telefonia móvel, você escolheria ?

A- 3\% de desconto em todas as ligações.

B- Uma em cada cinco ligações não terá desconto de $4 \%$ nas tarifas.

Q02. Qual plano de telefonia celular você prefere?

A- com reajuste de $3 \%$ ao ano em todas as ligações.

B- com reajuste de $4 \%$ ao ano nas tarifas, mas com o sorteio de 01 KIT-DESCONTO (isenção de reajuste) entre cinco clientes

Q03. Qual dos planos de telefonia celular abaixo, você prefere?

A- Todas as ligações com 3\% de desconto nas tarifas.

B- Plano com celular incluso e quatro a cada cinco ligações com desconto de $4 \%$ nas tarifas.

Q04. Qual plano de telefonia celular você prefere?

A- Plano com celular incluso e todas as ligações com 3\% ao ano de reajuste nas tarifas.

B- Reajuste de $4 \%$ ao ano nas tarifas, e sorteio de 01 KIT-

DESCONTO (isenção de reajustes) a cada cinco clientes..

Q05. Você foi a uma loja comprar um celular que custa R\$324,00, e nesta loja o vendedor lhe informa que o mesmo celular está sendo oferecido, em promoção, com desconto de $\mathrm{R} \$ 13,00$ em outra loja rede, que fica a 20 minutos de carro dali. Você iria até esta outra loja para participar desta promoção?
A- Sim
B- Não 


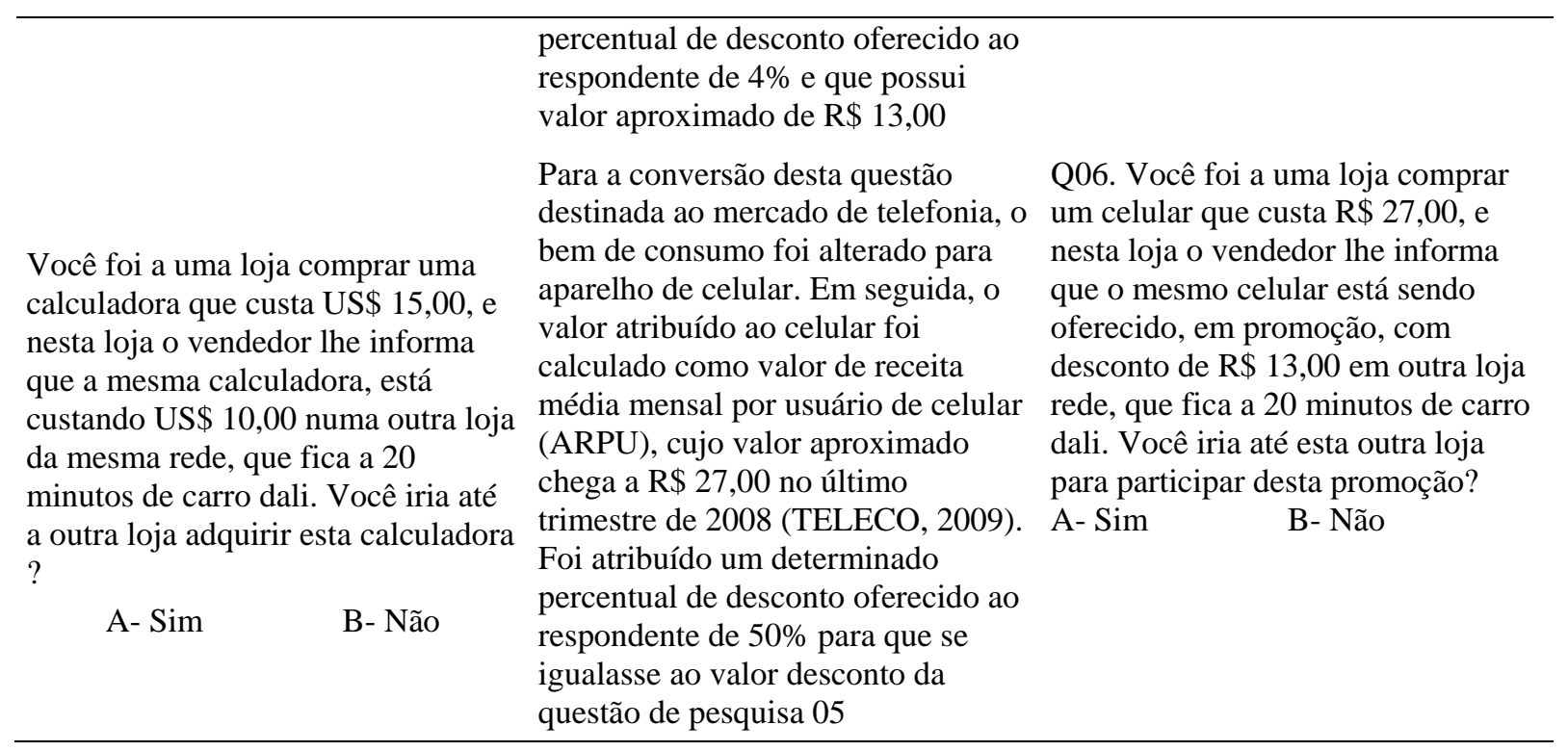

Nota. ${ }^{\text {(a) }}$ Conforme Kahneman, D., \& Tversky, A. (1979). Prospect theory: an analysis of decision under risk. Econometrica, 47(2), 263-291. doi: 10.2307/1914185 